\title{
ORGANISATIONAL MATTERS
}

\section{Leading organisational learning in health care}

\author{
J S Carroll, A C Edmondson
}

Qual Saf Health Care 2002;11:51-56

As healthcare organisations seek to enhance safety and quality in a changing environment, organisational learning practices can help to improve existing skills and knowledge and provide opportunities to discover better ways of working together. Leadership at executive, middle management, and local levels is needed to create a sense of shared purpose. This shared vision should help to build effective relationships, facilitate connections between action and reflection, and strengthen the desirable elements of the healthcare culture while modifying outdated assumptions, procedures, and structures.

W hat do the US Army, Royal Dutch Shell, General Electric, and Minneapolis Children's Hospitals and Clinics have in common? They are among many organisations actively engaged in developing advanced capabilities for organisational learning. The US Army is renowned for After Action Reviews (AAR) in which participants in training exercises or real events get together immediately afterwards to share observations and ideas in a blame-free discussion. AAR is part of a sophisticated learning structure that emerged after the Vietnam War and transformed the Army. ${ }^{1}$ Royal Dutch Shell was an early adopter of scenario planning techniques and uses these as learning tools to uncover assumptions and drive new ways of thinking and conversing through the company. Its CEO explained: "We think of planning as learning and corporate planning as institutional learning". General Electric made "boundarylessness" a cornerstone of its strategy, enacted through conferences, meetings, visits, and project teams that connect people inside and outside the company. ${ }^{3}$ Minneapolis Children's Hospitals and Clinics made patient safety a strategic goal and built learning mechanisms such as focused event studies, safety dialogues, and blameless reporting of problems into their work practices. ${ }^{4}$

See end of article for authors' affiliations $\ldots \ldots \ldots \ldots \ldots \ldots . . . \ldots$.

Correspondence to: Professor J Carroll, MIT Sloan School of Management,

50 Memorial Drive Cambridge, MA 02139 USA; jcarroll@mit.edu

Accepted for publication 15 January 2002

\section{HEALTH CARE AT A CROSSROADS}

Acording to Berwick and Nolan," "searching for one word to describe the state of mind of the physician in the United States today, we might choose beleaguered". The professional status of physicians is at its lowest, fewer people are entering the nursing profession, and financial pressures have created longer working hours and less resource support. In the past 2 years major panel reports have highlighted disturbingly high levels of preventable medical errors and tens of thousands of unnecessary deaths each year. ${ }^{67}$ Will the healthcare industry defensively reject the calls for action, or will these challenges spur learning and innovation in the organisations and systems through which healthcare is delivered?

We see healthy signs of a wave of innovation. Although there are deep anxieties and many sources of resistance to change in health care, there are also individuals and organisations which are exhibiting creativity and leadership. To support these efforts, we offer concepts and practical examples drawn from several industries including health care. Three ideas underlie our argument:

(1) Healthcare organisations can improve quality and other outcomes by enhancing their capabilities for organisational learning.

(2) Organisational learning requires leadership from executives, line (middle) managers, and informal network leaders throughout organisations.

(3) Leaders are more effective when they take a broad view of the interdependencies among individuals, teams, task flows, systems, and cultural meanings.

\section{ORGANISATIONAL LEARNING}

Organisational learning is a process of increasing the capacity for effective organisational action through knowledge and understanding..$^{8-10}$ The learning "process" is a cycle of action and reflection-that is, doing and thinking, performing and conversing. ${ }^{11-13}$ What is being learned, made more effective, and disseminated are "routines" for conducting work that accomplishes goals. ${ }^{14-16}$ Routines evolve over time as individuals get experience with tasks, people come and go, technologies change, priorities and policies shift, and best practices are shared. In health care, typical goals include improving patient well being, handling a greater case load with lower costs, attracting and retaining top quality staff, training residents, getting research grants, and enhancing reputation. Serving these goals are numerous work routines including patient admissions, delivery of care, billing, hiring of personnel, buying equipment, buildings maintenance, and creation of a mission and strategic plan. Some routines are simple and are carried out by one person, while other routines require coordinated action from many. Knowledge necessary to carry out these routines is stored in many different forms and locations, including procedure manuals, physical equipment and layout, and in individual minds. ${ }^{17}$

Although individual human beings are naturally programmed to learn, organisations are not. For example, learning may be inhibited by adherence to traditions or bosses who insist that "this is 
the way we do things around here" ${ }^{18}{ }^{19}$ Most learning that goes on in organisations is local, as individuals or groups perfect their skills and cope with the constraints and costs of dealing with other groups or "the system". Local learning is often hard to verbalise, is closely tied to the details of the work, and is difficult to transfer (often requiring apprenticeship or moving people). ${ }^{20-23}$ In the nuclear power industry, for example, information to prevent the Three Mile Island (TMI) disaster was available from several sources-similar prior incidents at other plants, recurrent problems with the same equipment at TMI, and the critique of engineers that operators had been taught to do the wrong thing in particular circumstances-yet nothing had been done to incorporate this information into operating practices. ${ }^{24}$

Organisations learn by creating opportunities for information flow and knowledge creation using a wide range of learning mechanisms such as after action reviews, audits, problem investigations, performance appraisals, simulation, and benchmarking. ${ }^{25}$ Some of these learning mechanisms are embedded in the work routines as staff give each other verbal and non-verbal feedback. Other learning can be carried out by participants after performing a task, or by outside auditors or researchers who report their observations and insights. Organisations typically use the results of these activities to standardise work practices, make knowledge more explicit, and control learning. ${ }^{26}$ For example, the decade after TMI saw dramatic increases in regulations, formal procedures, internal and external oversight, reporting requirements, training, measurement and information systems, staffing, and exchanges of best practices. ${ }^{27} 28$

A serious accident at a nuclear power plant requires a combination of active failures such as human errors and "latent failures". ${ }^{29}$ These latent failures are hidden deficiencies such as incorrect procedures, turf battles, overloaded employees, and non-functional back up systems that lie in wait for the right trigger. Safety and quality are enhanced by finding latent failures as they surface in near misses, hunting them down with audits and simulations, reducing the introduction of new latent failures, and proactively seeking out and experimenting with better ways to work..$^{2630} 31$ This requires broad participation, vigilance, open communication, and resources. ${ }^{32-34}$

Increasing bureaucratic controls and even mandating the use of learning mechanisms does not, however, guarantee learning or change in work practices. While controls are useful in addressing familiar and frequent problems, they may weaken the ability to address novel problems and see new opportunities. ${ }^{26}{ }^{35}$ In the nuclear power industry, for example, it took a decade of experience with problem reporting systems to realise that blaming individuals did not make the problems go away, but instead discouraged employees from reporting them. ${ }^{30}{ }^{36}$ Some managers were so confident of their plant's capabilities that they closed themselves off from criticism and learning opportunities, and their defensiveness eroded the trust of employees and regulators. ${ }^{37}$ A manager who scowls at a "complaining" employee or cuts travel funds to industry conferences may not realise that years later a problem could emerge that would have been prevented by one piece of information. In this way, policy decisions that drain resources away from learning can slowly and almost invisibly stifle innovation and growth.

Latent failures and system problems are difficult to perceive at a local level and thus difficult to act upon. ${ }^{26}{ }^{30}{ }^{35}$ Systemic organisational, political, and cultural issues are often invisible, too diffuse or confusing to address, or downplayed in the belief that focusing on systems excuses individual responsibility. Our mental models often lead us to well intentioned actions that help in the short run but create other delayed problems.9 ${ }^{98}$ Effective action on such problems requires understanding systemic interdependencies and leverage points, surfacing and challenging assumptions, communicating across groups, and mobilising change. This is what the recent Institute of Medicine report means by saying: "Trying harder will not work. Changing systems of care will" (page 4). ${ }^{39}$

It takes a combination of values, skills, and structures to support comprehensive systemic organisational learning. Organisations that value long term rather than short term performance and care about a wider range of outcomes (performance, safety, quality, environment) and stakeholders (shareholders, employees, customers, suppliers, community, society) are likely to recognise the need to learn and take the time to learn. ${ }^{103340}$ Such organisations cultivate a variety of skills or disciplines to support learning, including acknowledgement of doubt, collaborative inquiry, personal and shared visioning, conflict management, team learning, and systems thinking. ${ }^{94} 4142$ Numerous specific learning mechanisms can be used to stimulate creativity, bring in new information (for example, benchmarking, exchanges of personnel), experiment with new routines, give and discuss feedback, and disseminate new ideas. ${ }^{1025}$ Organisations committed to learning build supportive structures including information systems, training programmes, meetings, and coaching orientated managers who create psychological safety and invite feedback and participation. ${ }^{43}{ }^{44}$ These characteristics are illustrated below in a more specific discussion of health care.

\section{MENTAL MODELS OF ORGANISATIONAL LEARNING IN HEALTH CARE}

The implicit mental model or system of beliefs that governs learning in health care is "the application of a body of knowledge derived from medical science and perfected by a physician's own personal experience" ${ }^{45}$ In short, the best surgeon is the one who has done the same procedure hundreds of times. Thus, learning is typically viewed as individually focused training, continuing medical education to transfer best practices, and repetition to enhance skill. In fig 1 the boxes and arrows with heavy lines in loop 1 (indicated by the number $l$ in a small circle) indicate that training and repetition lead to expertise which improves outcomes and then enhances reputation. Reputation provides opportunities for more repetition and even greater expertise-a virtuous cycle.

We call these causal relationships a "mental model" to emphasise that this is a system of beliefs that interprets observations and influences behaviour. ${ }^{96}$ While it is true that

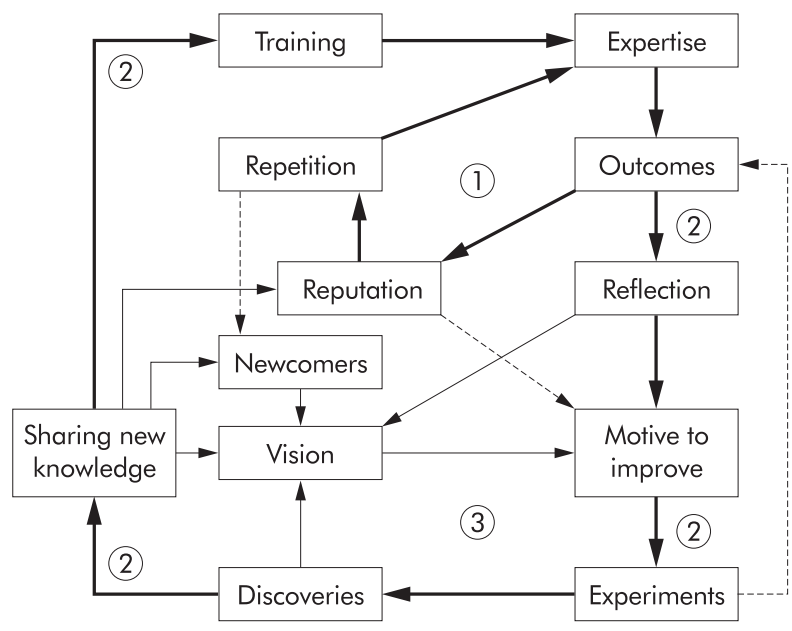

Figure 1 Illustrative mental models of organisational learning. Solid arrows represent relationships in which an increase in the cause produces an increase in the effect (e.g. more training leads to more expertise); dashed arrows indicate causes that produce opposite effects (e.g. a better reputation decreases motivation to improve). 
repetition generally increases expertise, this is not a universal or complete scientific theory of learning. In one study operating room teams with equal levels of experience learned at very different rates, depending on their ability to think about and discuss their experiences openly. ${ }^{47}$ There are many examples of "superstitious learning" in which people and organisations repeat behaviours that were associated with particularly positive results by chance but actually have no influence on outcomes. ${ }^{16}$ Doctors can get lots of experience doing the wrong thing such as routinely performing tonsillectomies, a common practice in past decades that is no longer considered beneficial. ${ }^{48}$

Much of the emphasis in developing medical expertise focuses on "exploiting" what is known, ${ }^{49}$ as represented in the "learning from experience" portion of fig l (loop l). The goal is to reduce skill based errors (slips and lapses) ${ }^{29}$ and improve timing and coordination at performing a technical task. It is a special kind of standardisation since every patient is unique (unlike a factory that can standardise its inputs). Physicians learn to perfect their technique and to adjust to the range of variation they experience on a standard procedure such as heart valve repair. But "the important question isn't how to keep bad physicians from harming patients; it's how to keep good physicians from harming patients".$^{50}$ The "learning from experience" model is insufficient for at least two reasons.

Firstly, even in highly repeatable tasks, repetition may have unintended undesirable (and often delayed) side effects for the larger scale system. ${ }^{938}$ For example, doctors and nurses may become like bored factory workers and newcomers may be disparaged for their lack of experience. If experienced practitioners get demotivated, reduce their interest in learning new things, or move on to more interesting work, or talented young people avoid areas of medicine where the challenges are predictable, then organisations may fail to learn and performance may suffer. Expertise can be a "competency trap" in which complacency and commitments to the skills that made individuals and organisations successful prevent growth and change. ${ }^{16-185152}$ Figure 1 therefore includes arrows from outcomes and reputation that inhibit reflection and motive to improve. Without reflection on disappointing and surprising results, the organisation is not aware of the need for change that would trigger experimentation and discovery which, if shared, would ultimately inform training and practice (follow loop 2 around the perimeter of fig 1 ). Hence, if the discovery loop is inhibited, learning may be limited to incremental advances. ${ }^{11}{ }^{53}$

Secondly, not all problems can be reduced to technical solutions. Different kinds of training and experience are needed to handle a flow of unpredictable cases or to make new discoveries and incorporate them into practice. ${ }^{26} \mathrm{~A}$ patient wants his/her tonsillectomy performed by a skilled surgeon but, if a tonsillectomy is the wrong thing to do, then focusing attention on the surgeon's skill is missing the point. Rule based and knowledge based errors involve applying the wrong solution, however skilfully, to the problem at hand or lacking the appropriate knowledge (which could be a system problem rather than a matter of individual competence). ${ }^{29}$ Tasks that require interdependent action among a team or among departments in a hospital are not purely technical problems. ${ }^{30}$ For example, the study of operating room teams noted above and described in box 1 found dramatically different rates of learning depending on whether or not the surgeon team leader created an open and participative climate that allowed communication across professional boundaries. ${ }^{47}{ }^{54}$ In another study $^{55}$ an intensive care unit learned to combine expert technical skills with flexibility and empowerment of front line individuals and teams.

We consider that healthcare organisations must exploit technical skills, refining performance of repetitive tasks but, at the same time, they must explore potential opportunities, rethink assumptions underlying their practices, and seek sig-

\section{Box 1 Learning as a team process}

In a study of 16 hospitals implementing a new technology for minimally invasive cardiac surgery, those in which surgeons empowered the operating room team-explicitly recognising the importance of each member's role and contribution to the learning effort-had better outcomes. The cardiac surgery department of one of the most successful of these hospitals had recently hired a young surgeon who wanted to pursue innovation and he led an operating room team in the technology implementation effort. He recognised that the new procedure would require the team to adopt a very different style of working together, explaining that "the ability of the surgeon to allow himself to become a partner, rather than a dictator, is critical". "For example, you really do have to change what you're doing [during an operation] based on a suggestion from someone else on the team. This is a complete restructuring of the [operating room] and how it works." Team members were picked because of their experience of working together and they responded enthusiastically to this approach. One noted that the "hierarchy [has] changed", creating a "free and open environment with input from everybody". Another said: "I'm so excited about [the new procedure]. It has been a model, not just for this hospital but for cardiac surgery. It is about what a group of people can do." He explained that the team got better because "the surgeon said: 'You guys have got to make this thing work'. That's a great motivator."

nificant innovations. ${ }^{49}$ The lower part of fig 1 illustrates how exploration may emerge from disappointing outcomes (that prompt reflection ${ }^{1126}$ ) or from a vision of possibilities (developed from benchmarking or brainstorming ${ }^{56}$ ). For example, the death of Libby Zion from an adverse interaction of two medications "has changed residency training forever ${ }^{\prime \prime 57}$ because of public recognition of the dangers of sleep deprived and overworked residents. However, reducing residents' hours or using a night float takes resources away from current routines and actually may increase harm by decreasing continuity of care. Furthermore, the results of experimentation are usually worse in the short run (shown in fig 1 by a negative arrow from experiments to outcomes); change efforts typically follow a "worse before better" scenario. ${ }^{58}$ An early focus on results can generate anxiety and inhibit experimentation ${ }^{59}$ but, in the long run, experimentation leads to discovery that improves practice (fig 1, loop 2) and also stimulates vision that motivates improvement and further discovery (fig 1, loop 3). Organisations must therefore balance their learning needs, without always knowing what kinds of problems they will face or whose participation will be needed to adapt innovations to existing processes and practices.

The relationships portrayed in fig 1 are only a starting point for understanding how healthcare organisations can learn. For example, reflection is key to both action and learning, ${ }^{1160}$ but reflection is a complex process that is influenced by many characteristics of individuals and organisations. Individual reflection takes discipline, analytical skill, and creativity, but collective reflection adds elements of communication skills and social relationships. ${ }^{914} 44$ For example, is a Morbidity and Mortality Conference a "cultural ritual" that focuses on what individuals could do differently, thereby reinforcing shame and blame, or a process for identifying latent failures that lie in wait for someone to trigger them $?^{50}$ Broadly construed, a box labelled "reflection" could be inserted between every link in fig 1; how, for example, do discoveries become vision or outcomes become reputation? Each link is similarly complex. Although people generally reflect more on bad outcomes, this 
depends greatly on whether there is time to reflect, social support and skill for reflection, mechanisms for collective feedback and reflection, a culture that encourages learning from problems rather than defending against blame, and many other factors. ${ }^{11}{ }^{30}$ It should not therefore be surprising that development of organisational learning capabilities requires participation and leadership from a wide range of organisation members.

\section{LEADERSHIP OF ORGANISATIONAL LEARNING}

Just as safety is a property of a system rather than solely the result of individual skill, ${ }^{3061}$ leadership is also a system property. In a time of rapid changes in technology, demographics, markets, and organisation forms, leadership is an essential function to prepare and mobilise organisation participants for change ${ }^{62}$ and to create a balance between exploitation of current capabilities and exploration and development of new capabilities. "The manager does things right; the leader does the right thing". ${ }^{3}$

Mention of "the leader" should not, however, be taken to mean the CEO or other executives. Leadership must be distributed broadly if organisations are to increase their capacity for learning and change and therefore to flourish in a complex and changing environment. Specifically, we discuss executive or strategic leadership at the top of an organisation, line leadership from managers in the middle, and informal or network leadership from individuals throughout the organisation. ${ }^{64}$

Executive leaders are often considered the legitimate visionaries and structural designers of the organisation. For example, Julie Morath, the chief operating officer of Minneapolis Children's Hospitals and Clinics, framed this vision for patient safety: "The culture of health care must be one of everyone working together to understand safety, identify risks, and report them without fear of blame. We must look at ways of changing the whole system when we manage to zero defects". ${ }^{4}$ Vision can create a sense of shared purpose. Guiding ideas shape thinking, frame opportunities, and orientate the organisation toward particular values and criteria for success. Morath changed the language from threatening terms such as "errors" and "investigations" to "accidents" and "analysis". She created structures such as the Patient Safety Steering Committee to provide resources and opportunities to engage cross-disciplinary participation. Executive leaders also provide protection or psychological safety ${ }^{33}$ for and mentoring of line leaders and informal network leaders who do most of the work of change. Because they are a focus of attention for the organisation, senior managers are important role models who embody the organisation's norms, values, and culture. Brock Nelson, CEO of Children's Hospitals and Clinics, openly describes his "personal epiphany" in being able to enact a new policy of disclosing more information and personally apologising to a family that had lost a teenage child who had initially been misdiagnosed. ${ }^{4}$

However, even CEOs cannot readily change a culture. Rather than opposing the culture, it is generally more effective to address acknowledged problems in new ways and to "tilt" the culture by reinterpreting new actions as consistent with existing cultural strengths. ${ }^{19}$ For example, it is said that medicine leaves people "isolated in their discipline specific domains and 'tainted' by traditional disciplinary hierarchies, boundaries and biases". ${ }^{65}$ Many physicians feel uncomfortable being "part of the team as opposed to being the sole decision maker" ${ }^{66}$ If "among all of the skills for improvement, the most crucial one may be the skill to cooperate across traditional boundaries", ${ }^{67}$ then how do we change an individualistic culture into a teamwork culture? Senior clinical leaders and executives can articulate and champion new values, but that will have little impact without opportunities for people to work together on common problems (see box 1). Instead of addressing culture

\section{Box 2 Empowering local leadership}

At Minneapolis Children's Hospitals and Clinics a clinical nurse specialist and a pharmacist in haematology/ oncology wanted to do something about patient safety at the local level. With support from the pharmacy manager, the nurse and pharmacist started a safety action team of cross-functional front line service workers to meet monthly to discuss medication safety issues. The consistent and frequent message from senior leadership that patient safety was a priority allowed these employees to overcome numerous barriers such as status differences, already heavy workloads, and general resistance to changes in how things get done in the hospital setting. The concept spread to other departments and then became an organisational initiative for every clinical unit manager.

or teamwork directly, executives could support new ways to improve surgical team performance, for example, and then portray teamwork as supporting culturally accepted goals and values of excellence, learning, and caring. Participants then experience for themselves how new ways of acting can meet shared goals, gradually shifting cultural beliefs, values, and assumptions.

Although senior managers can create vision and strategy, "nothing can start without committed local line leaders". ${ }^{64}$ For example, it was not high level management support that was decisive in successfully implementing the new technology in the scenario in box 1, but the way the surgical team leaders fostered an atmosphere of learning including acknowledgement of doubt, encouragement of communication, and real time team learning. ${ }^{4}$ Any experiment carries the risk of failure, but every failure is a learning opportunity, especially small failures. ${ }^{68}$ In a medical culture of infallibility, however, any failure "can meet with resistance among physicians and managers for whom success is the only acceptable result". ${ }^{69}$ Line leaders thus bear a considerable burden-asked by executive leaders to make the vision come to life, asked by subordinates to coordinate and support their work, asked by everyone to solve problems and make decisions. From the viewpoint of organisational learning, they are critical for encouraging and supporting practical experiments and learning efforts. When experiments bear fruit, they are the teachers and disseminators of new practices. But they are always at risk of having their efforts resisted, their successes misinterpreted, their investments rejected, and their executive support withdrawn.

Informal network leaders are the community builders who weave organisations together. With little or no formal position or authority, they turn this weakness into strength by demonstrating commitment when they act from personal conviction. The dissenting voice can often do more to enhance group creativity and change underlying attitudes than coercive majorities or hierarchical leaders who demand compliance. ${ }^{70}$ The example described in box 2 demonstrates how two front line employees drew on their personal relationships, attracted modest support from management, and unleashed the creativity and commitment of the broader organisation. In order to stimulate innovation and change without creating resistance, informal leaders need sensitivity to the culture and politics of the organisation. By building informal networks, linking innovators with internal and external resources, creating communication structures to bridge boundaries, and finding ways to build coalitions within the existing power structure, ${ }^{71}{ }^{72}$ they accelerate organisational learning.

\section{LEADERSHIP CHALLENGES OF HEALTH CARE}

Leaders face particular problems in healthcare organisations where the cultural institutions and work practices that 
support individual expertise and autonomy can also inhibit information flow and collective learning. The task of caring for individuals with unique combinations of needs is complex and ever changing: the knowledge base of medicine continues to grow, technology advances, payers demand lower costs, and the legal system seems poised to find scapegoats for any disappointment.

Healthcare organisations are adept at local learning, but many practitioners resist standards and guidelines at the organisational level as infringements on their professional standing. Standardisation also can drive out innovation. Even the best teaching hospitals have ad hoc work practices that vary from department to department and tend to lionise surgeons who exemplify the individualistic culture. However, the kind of standardisation that is needed is not telling surgeons how to operate, but rather developing systems of communication and work practices that ensure that patients get the right drug at the right time, the right test at the right time, and that the right kinds of conversations are encouraged to support feedback and discovery (see, for example, a case study of the implementation of a "care path" for cardiac surgery which highlights the opportunity to standardise certain tasks without impinging on the autonomy of physicians and other clinical decision makers ${ }^{73}$ ). Such organisational discipline has often eluded health care, while clinical and professional expertise continue to make remarkable advances. Healthcare organisations face particular barriers to systemic organisational learning from powerful status differences that inhibit open inquiry and collaborative learning. These barriers may be surmountable when committed individuals and organisations take action on local opportunities to produce small wins, as illustrated in our examples; however, industry wide attention by opinion leaders to the need for and the barriers to learning may also be required to enable substantial change to occur.

The trust and safety needed to engage open participation in a learning process is hard to build but easy to destroy in reacting to the kind of pressure that emerges in a highly publicised signal event such as the Dana Farber case. ${ }^{74}$ It is tempting to take the advice of legal experts and try to avoid giving out any risky information. Yet the experience at Children's Hospitals and Clinics and elsewhere shows that candour supports learning, builds a positive culture, and may head off more expensive legal actions.

\section{CONCLUSIONS}

Leaders at every level need the wisdom to understand their role in creating conditions and physical space for safety and quality. Executives have to articulate a compelling vision of a learning culture that helps stakeholders to see investments in organisational learning as supportive of common goals. In moving to a focus on systems and learning, leaders serious about improvement need to model and reward reporting and learning from mistakes and near misses, rather than blaming individuals and suppressing information when bad events occur. Although there may be some errors that cannot be tolerated, the majority are honest mistakes that reveal system vulnerabilities. Leaders should create the psychological safety ${ }^{33} 75$ for errors to be discussed, while also inspiring individuals and the organisation to achieve a high standard of care. They must then persist as stakeholders discover that diverting resources to learning and process redesign will often mean that short term financial and production indicators look worse before they get better.

There is no single answer to strengthening organisational learning. Organisations must support local learning and standardised routines. However, standardisation must be balanced with attitudes and structures that encourage exploration and discovery. Leaders at every level can help to mobilise the participation from key stakeholders needed for systemic

\section{Key messages}

- Healthcare organisations can improve quality and safety by enhancing their capabilities for organisational learning.

- Organisational learning is a process of increasing knowledge and innovating work routines through the interplay of action and reflection that is more extensive than individually focused training and repetition.

- Learning in organisations is inhibited by such factors as tradition, outdated procedures, values, structures, and tacit "mental models" about how work gets done.

- Effective organisational learning is supported by cultural values of openness and excellence; learning mechanisms that encourage information flow, challenge assumptions, and aid systems thinking; and commitment of resources.

- Organisations have to balance incremental improvements and standardisation based on existing knowledge with more radical and uncertain innovations.

- Organisational learning and change require leadership from executives, line managers, and informal network leaders throughout organisations.

- Leaders should create purpose, help interpret situations in new ways, build trust, model new ways of thinking and acting, and take a broad view of the interdependencies of individuals, teams, task flows, systems, and cultures.

change. ${ }^{76}$ Effective leadership at every level requires understanding task and information flows as well as political interests and cultural assumptions. ${ }^{37}$ Leaders create a sense of shared purpose, build effective relationships, and make connections between action and reflection in enabling actionable knowledge and energising knowledgeable action.

\section{ACKNOWLEDGEMENTS}

The authors wish to express their appreciation to Laura Feldman and Jenny Rudolph for comments on an earlier draft.

\section{Authors' affiliations}

J S Carroll, MIT Sloan School of Management, Cambridge, MA 02139, USA

A C Edmondson, Harvard Business School, Boston, USA

\section{REFERENCES}

1 Sullivan GR, Harper MV. Hope is not a method: what business leaders can learn from America's Army. New York: Random House, 1996.

2 DeGeus A. Planning as learning. Harvard Business Review March/April 1988: 70-4.

3 Tichy NM, Sherman S. Control your destiny or someone else will: how Jack Welch is making General Electric the world's most competitive company. New York: Doubleday, 1993.

4 Edmondson A, Roberto M, Tucker A. Children's Hospitals and Clinics. HBS case \#9-302-050. Boston, MA: Harvard Business School Press, 2001.

5 Berwick DM, Nolan TW. Physicians as leaders in improving health care. Ann Intern Med 1998; 128:289-92.

6 Kohn JT, Corrigan JM, Donaldson MS, eds. To err is human: building a safer health system. Washington DC: National Academy Press, 1999.

7 Quality Interagency Coordination Task Force. Doing what counts for patient safety: Federal actions to reduce medical errors and their impact. Washington DC: Quality Interagency Coordination Task Force, 2000.

8 Fiol CM, Lyles MA. Organizational learning. Acad Manage Rev 1985;10:803-13.

9 Senge P. The fifth discipline. New York: Doubleday, 1990.

10 Garvin D. Learning in action: a guide to putting the learning organization to work. Boston, MA: Harvard Business School Press, 2000

11 Argyris C, Schön D. Organizational learning II: Theory, method, and practice. Reading: Addison-Wesley, 1996.

12 Daft RL, Weick KE. Toward a model of organizations as interpretation systems. Acad Manage Rev 1984;9:284-95.

13 Kolb DA. Experiential learning as the source of learning and development. Englewood Cliffs, NJ: Prentice-Hall, 1984.

14 Crossan MM, Lane HW, White RE. An organizational learning framework: from intuition to institution. Acad Manage Rev 1999;24:522-37

15 Huber GP. Organizational learning: the contributing processes and the literatures. Organization Sci 1991;2:88-115.

16 Levitt B, March JG. Organizational learning. Ann Rev Sociol $1988 ; 14: 319-40$ 
17 Argote L, Ingram P. Knowledge transfer: a basis for competitive advantage in firms. Organizational Behavior and Human Decision Processes 2000;82: 150-69.

18 Oliver C. The antecedents of deinstitutionalization. Organization Stud 1992;13:563-88

19 Schein EH. The corporate culture survival guide. San Francisco: Jossey Bass, 1999.

20 Carlile PR. A pragmatic view of knowledge and boundaries: boundary objects in new product development. Organization Sci 2002 (in press).

21 Gruenfeld DH, Martorana PV, Fan ET. What do groups learn from their worldiest members? Direct and indirect influence in dynamic teams. Organizational Behavior and Human Decision Processes 2000;82:45-59

22 Nonaka I, Takeuchi H. The knowledge-creating company: how Japanese companies create the dynamics of innovation. New York: Oxford University Press, 1995.

23 Von Hippel E. "Sticky information" and the locus of problem solving: implications for innovation. Manage Sci 1994;40:429-39.

24 Kemeny JG, Babbitt B, Haggerty PE, et al. Report of the President's commission on the accident at Three Mile Island. New York: Pergamon, 1979

25 Popper M, Lipshitz R. Organizational learning mechanisms: a structural and cultural approach to organizational learning. J Appl Behav Sci 1998; 34:161-79.

26 Sitkin SB, Sutcliffe KM, Schroeder RG. Distinguishing control from learning in total quality management: a contingency perspective. Acad Manage Rev 1994; 18:537-64.

27 Carroll JS, Rudolph JW, Hatakenaka S. Learning from organizational experience. In: Easterby-Smith M, Lyles MA, eds. Handbook of organizational learning and knowledge. Oxford: Blackwell, 2002 (in press)

28 Rees JV. Hostages to each other: the transformation of nuclear safety since Three Mile Island. Chicago: University of Chicago, 1994.

29 Reason J. Human error. New York: Cambridge University, 1990.

30 Reason J. Managing the risks of organizational accidents. Brookfield, VT: Ashgate, 1997.

31 Schaaf TW van der, Lucas DA, Hale AR, eds. Near miss reporting as a safety tool. Oxford: Butterworth-Heinemann, 1991.

32 Marcus AA, Nichols ML. On the edge: heeding the warnings of unusual events. Organization Sci 1999;10:482-99.

33 Edmondson A. Psychological safety and learning behavior in work teams. Admin Sci Q 1999;44:350-83.

34 Weick KE, Sutcliffe KM, Obstfeld D. Organizing for high reliability: processes of collective mindfulness. Res Organizat Behav $1999 \cdot 21 \cdot 81-123$

35 Rudolph J, Repenning N. Disaster dynamics: understanding the role of quantity in organizational collapse. Admin Sci Q 2002 (in press).

36 Carroll JS. Incident reviews in high-hazard industries: sensemaking and learning under ambiguity and accountability. Ind Environ Crisis $Q$ 1995;9:175-97.

37 Carroll JS, Hatakenaka S. Driving organizational change in the midst of crisis. MIT Sloan Manage Rev 2001 ; 42:70-9

38 Sterman J, Repenning N, Kofman. Unanticipated side effects of successful quality programs: exploring a paradox of organizationa improvement. Manage Sci 1997:43:503-21.

39 Institute of Medicine. Crossing the quality chasm: a new health system of the 21 st century. Washington DC: National Academy Press, 2001

40 Pfeffer J, Sutton R. The knowing-doing gap: how smart companies turn knowledge into action. Boston, MA: Harvard Business School Press, 1999.

41 Isaacs W. Dialogue and the art of thinking together. New York: Currency Doubleday, 1999

42 Schulman PR.The negotiated order of organizational reliability. Admin Society 1993;25:353-72.

43 Davenport T, Prusak L. Working knowledge. Boston, MA: Harvard Business School Press, 1997

44 Edmondson A. The local and variegated nature of learning in organizations. Organization Sci 2002 (in press)

45 Bohmer RMJ, Edmondson AC. Organizational learning in health care. Health Forum J 2001;March/April, 33.

46 Carroll JS. Organizational learning activities in high-hazard industries: the logics underlying self-analysis. J Manage Studies 1998;35:699-717.
47 Pisano GP, Bohmer RMJ, Edmondson AC. Organizational differences in rates of learning: evidence from the adoption of minimally invasive cardiac surgery. Manage Sci 2001;47:752-68.

48 Bakwin H. Pseudodoxia pediatrica. N Engl J Med 1945;232:691.

49 March JG. Exploration and exploitation in organizational learning. Organization Sci 1991;2:71-87.

50 Gawande A. When doctors make mistakes. New Yorker 1 February 1999:40-55

51 Szulanski G. Exploring internal stickiness: impediments to the transfer of best practices within the firm. Strategic Management J 1996;1 17:27-43.

52 Tucker A, Edmondson A, Spear S. When problem solving prevents organizational learning. J Organizational Change Manage 2002 (in press).

53 Miner AS, Mezias SJ. Ugly duckling no more: pasts and futures of organizational learning research. Organization Sci 1996;7:88-99.

54 Edmondson A, Bohmer R, Pisano G. Speeding up team learning. Harvard Business Rev 2001 ;October: 5-1 1.

55 Roberts KH, Bea R. Must accidents happen? Lessons from high-reliability organizations. Acad Manage Exec 2001;15:70-8.

56 March JG, Sproull L, Tamuz M. Learning from samples of one or fewer. Organization Sci 1991;2:1-13.

57 McCall TB. No turning back: a blueprint for residency reform. JAMA 1989;261:909-10.

58 Repenning NP, Sterman JD. Getting quality the old-fashioned way: self-confirming attributions in the dynamics of process improvement. In Scott R, Cole R, eds. Improving research in total quality management. Newbury Park, CA: Sage, 2000.

59 Stone D, Eddy E.A model of individual and organizational factors affecting quality-related outcomes. J Qual Manage 1996;1:21-48.

60 Weick KE. Sensemaking in organizations. Thousand Oaks, CA: Sage, 1995.

61 Leape L, Kabcenell Al, Gandhi TK, et al. Reducing adverse drug events: lessons from a breakthrough collaborative. It Comm J Qual Improve 2000;26:321-31

62 Kotter JP. Leading change. Boston: Harvard Business School Press, 1996.

63 Bennis W. On becoming a leader. Reading, MA: Perseus, 1994: 45

64 Senge $P$. Leading learning organizations: the bold, the powerful, and the invisible. In: Hesselbein F, Goldsmith M, Beckhard R, eds. The leader of the future. San Francisco: Jossey Bass, 1996: 41-57.

65 Barr H. Working together to learn together: learning together to work together (commentary). J Interprofessional Care 2000;14:177-8.

66 Parker DL, Wertheimer DS. Incorporating internal medicine residents into an interdisciplinary geriatric assessment team. Acad Med 1997:72:451.

67 Berwick DM, Nolan TW. Physicians as leaders in improving health care. Ann Intern Med 1998;128:289-92.

68 Sitkin SB. Learning through failure: the strategy of small losses. Res Organiz Behav 1992;14:231-66.

69 Berwick DM. Developing and testing changes in delivery of care. Ann Intern Med 1998;128:651-6.

70 Nemeth CJ. Differential contributions of majority and minority influence. Psychol Rev 1986;93:23-32.

71 Meyerson DE, Scully MA. Crossroads: tempered radicalism and the politics of ambivalence and change. Organization $\mathrm{Sci}$ 1995;6:585-600

72 Cook SDN, Brown JS. Bridging epistemologies: the generative dance between organizational knowledge and organizational knowing. Organization Sci 1999:10:381-400.

73 Weber J. Massachusetts General Hospital: CABG Surgery. HBS Case \# 9-696-015. Boston, MA: Harvard Business School Publishing, 1999

74 Bohmer R, Winslow A. The Dana-Farber Cancer Institute. HBS Case \# 699-025. Boston, MA: Harvard Business School Publishing, 1999

75 Edmondson AC. Learning from mistakes is easier said than done. J Appl Behav Sci 1996;32:5-28.

76 Bartunek JM. Changing interpretive schemes and organizational restructuring: the example of a religious order. Admin Sci Q 1984;29:355-72.

77 Ancona D, Kochan T, Scully M, et al. Managing for the future: organizational behavior and processes. Boston: South West, 1999. 